International Journal of Instruction e-ISSN: 1308-1470 • www.e-iji.net

Article submission code: 20201203171916

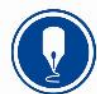

October $2021 \bullet$ Vol.14, No.4

p-ISSN: 1694-609X

pp. $891-912$

Received: 03/12/2020

Revision: 04/05/2021
Accepted: 29/05/2021

OnlineFirst: 03/09/2021

\title{
Investigation of the Relationship between Transformational Leadership Style and Teachers' Successful Online Teaching during Covid-19
}

\section{Asmahan Masry-Herzallah}

Dr., corresponding author Al Qasemi Academic-College of Education, The Hebrew University of Jerusalem, Israel, asmahan.masry@mail.huji.ac.il

Yuliya Stavissky

Ahad Haam school Betah Tikva, Israel, 123yul45@walla.co.il

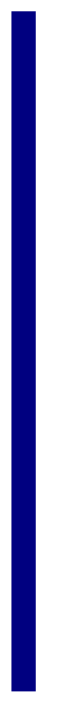

The Corona pandemic has engendered drastic change throughout the world and schools in most countries have, relatively quickly, been required to transfer from frontal traditional learning to online learning. The research investigated the relationship between transformational leadership style and teaching mediated by school communications and moderated by sector (Jewish and Arab) in education systems in Israel during the Corona pandemic. 331 Jewish and Arab teachers participated in the research, expressing attitudes on the principals' leadership, the quality of school communications and the success of their online teaching during the Corona crisis. A positive correlation was found between principals' transformational leadership style and the success of online teaching, and the quality of communications in the school mediated this correlation. It was also found that the Jewish teachers reported more successes in online teaching and that the indirect correlation between transformational leadership and successful online teaching, through the quality of school communications, was moderated by population sector, so that it was stronger among Jewish teachers in comparison to Arab teachers. These findings have significant implications to improve organisational effectiveness, especially in the transition to online learning, and especially regarding the cultural uniqueness of different sectors.

Keywords: transformational leadership, online learning, online teaching, school communications, organisational change

\section{INTRODUCTION}

A consensus in research literature indicates a clear correlation between the principal's leadership style and the teachers' functioning. Studies that investigated the influence of transformational leadership in schools found, for example, that this leadership style correlated positively with teachers' general commitment to school (Ismail et al., 2019; Masry-Herzallah \& Arar, 2019; Ross \& Gray 2006a) and more specifically with their commitment to organisational changes (Masry-Herzallah \& Arar, 2018; Hallinger,

Citation: Masry-Herzallah, A., \& Stavissky, Y. (2021). Investigation of the relationship between transformational leadership style and teachers' successful online teaching during covid-19. International Journal of Instruction, 14(4), 891-912. https://doi.org/10.29333/iji.2021.14451a 
2019), to the promotion of pedagogic innovation (Amzalag \& Masry-Herzallah, 2021), to optimal communication (Yukl, 2010) and to the implementation of Online learning (Dexter, 2011). Research has also found that principals with a transformational leadership style are revealed as more effective during organisational change (Pillai et al., 2007), because they influence their subordinates' beliefs, approaches and basic values, and consequently improve teachers' willingness for changes (Fullan, 2007). A principal with a transformational leadership style positively influences the teacher's work, during routine periods and even more so during periods of change since they construct and maintain connections between school staff members to enable free flow of knowledge and information (Bass \&Avolio, 1994). These connections develop and are stimulated by both informal and formal interactions, which reinforce the staff's cohesion and satisfaction through communication, helping to create shared meaning for them all (Sproull et al., 1991). Indeed, studies indicate that the transformational style correlates positively with clear, open, transparent and bi-directional communications and the organisation's climate (Mumford et al., 2000), and also encourages the teachers to promote innovative behaviour in the school (Balkar, 2015; Bawuro et al., 2018).

Research has also found that the quality of an organisation's communications is the principal vehicle for the creation of willingness for change (Armenakis et al., 2002; Bernerth, 2004) and that communication is essential for effective realisation of organisational change (Richardson \& Denton, 1996; Schweiger \& Denisi ,1991). Thus too, the quality of communications often determines how employees fill in lacking information when the situation is unclear. If the quality of communications is low, people will tend to become more cynical (Reichers et al., 1997). The transition to online learning following the outbreak of the Corona virus constitutes a significant change in school teaching and learning methods. This can be seen as an organisational change, one that includes much ambiguity, uncertainty and may often generate frustration.

Over the last decade, online learning has become an important element of schools, both during routine and emergency periods, because of its flexibility and the opportunities that it offers to students in different environments, and geographical regions (central and peripheral). However, the change during the Corona crisis is sharp and rapid. The implementation and use of technology-assisted learning, which has been expressed most forcefully during the pandemic, is a complex process necessitating a broad range of essential knowledge and skills from educational leaders for the success of this sort of learning (Yahay \& Raman, 2020). The use of these skills depends on trust, cooperation and amenability between the teaching staff, students and parents to promote teaching practices appropriate for online learning. As noted, research has indicated the effectiveness of transformational leadership in the successful implementation of school goals during crises (Pillai et al., 2007) and even in the implementation of online learning (Rupp, 2016). However, these studies did not examine the role of transformational leadership in schools and the correlation between this role and the functioning of teachers in online teaching during a severe and rapid-onset crisis such as the Corona pandemic that has caused the closure of schools around the world, causing a sharp transition to online learning as an alternative model for the crisis. Due to this situation teachers were required to adapt to sharp changes and teach in a new and unfamiliar way. 
The current research contributes new knowledge to the literature on online learning indicating that teachers' perceive the transformational leadership style and effective school communications as antecedents to their perception of success in online teaching during the period of Corona crisis. To the best of our knowledge, these correlations have not been examined previously, specifically in the period of Corona crisis. Based on the Full Range Leadership Model (Bass, 1985; Bass \& Avolio, 1990), and against a background of poor knowledge regarding the importance of the school principal's transformational leadership style during crises, the present study examines the role of the transformational leadership style as it affects the success of school teachers' online teaching and the role of school communications in this process, also comparing the responses of Jewish and Arab teachers.

This study is unique because none of the above-mentioned studies considered the role of transformational leadership style and school communications as antecedents to the success of teachers, from two sectors (cultures) in Israel (Jewish and Arab) in online teaching during the Corona crisis. Thus, the current research adds to the literature on online learning, enhancing existing knowledge on culture-sensitive online teaching in routine times and in times of emergency. It is important to note that there is obvious inequality in Israel between the Jewish and Arab communities. For example, hundreds of thousands of Arab families do not have access to the technological means necessary for online learning (Dahan et al., 2020). It is well-known that there is a digital gap between Jewish and Arab societies (Ganayem, 2018), in addition to cultural gaps that may influence the teaching and learning processes in the online space (Amzalag \& Masry-Herzallah, 2021). Thus, the present study compares the influence of the principals' style on Jewish and Arab teachers' online teaching and suggests that the principal's influence in the Arab school is more moderate, since there are additional background factors and complexities that influence the success of online learning and also the quality of communications in the Arab education system.

Therefore, in this study, special attention was given to the prediction of success in online teaching during the period of the Corona crisis. The current research aimed to answer the following questions:

1. Is there a correlation between the principal's transformational leadership style and the school's success in online teaching?

2. What is the role of school communications in the correlation between the principal's transformational leadership and the school's success in online teaching?

3. Is there a difference between Jewish and Arab teachers in the correlation between the principal's transformational leadership and the school's success in online teaching and school communications? 


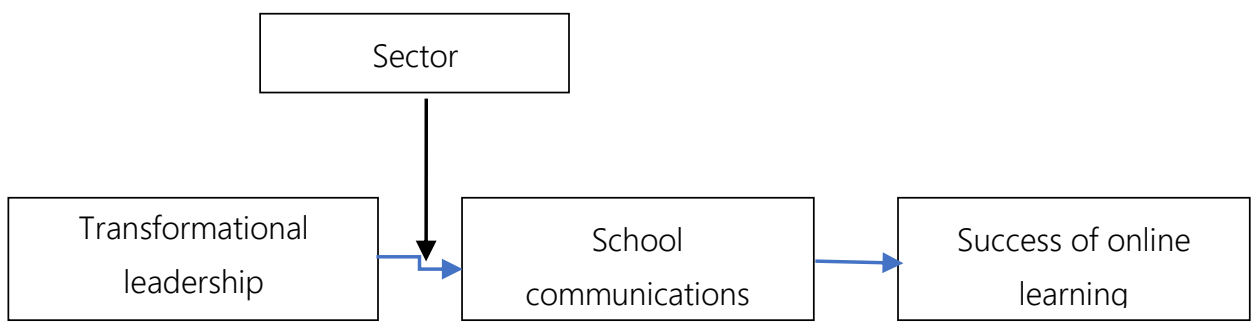

Figure 1

The research model

\section{Literature Review}

\section{Online learning and transformational leadership}

Online learning is an interdisciplinary field that is constantly evolving, and recently has received considerable attention (Bozkurt \& Sharma, 2020). It may be described as using technology to provide access to learning experiences and improve educational opportunities for learners (Moore et al., 2011). It allows connectivity, flexibility, and the ability to promote varied interactions; it can be delivered in various ways such as text, pictures, video, simulation; the access to materials can be given at any time and in any location (Moor et al., 2011; Rajab, 2018). Online learning can be performed synchronously or asynchronously. In asynchronous learning, the technology connects different students with teachers without any dependence on a particular shared time and place in order to conduct learning activities (Burdina et al., 2019; Reid-Martinez \& Grooms, 2018). Synchronous learning also exploits technological tools, however in this case the instructor and students need to be present during the lesson at the same time, although they may be in different geographical locations (Chauhan, 2017).

Online learning (both synchronous and asynchronous) which often relies on written communication, can be more well-thought through and deeper than oral communication (Fedynich et al., 2015). Exposure to pedagogic applications and online learning strategies, may help the students to function better in the technological environment throughout the learning and has great influence in achievement (Yuliyatno et al., 2019).

In recent years, an increasing number of researchers have begun to study online learning in schools. These studies indicate that online learning does not suit every student in the education system and may affect the principle of equal education among students (Masry-Herzallah \& Stavissky, 2021; Schleicher, 2020). This is due to the fact that not all students in the education system enjoy the same environmental conditions at home that allow them to study online (Welner, 2020). In addition, the presence and support of parents who can assist their children with these studies is not available to all students, because not all parents are accessible for this purpose or technologically capable. Augmenting the digital divide, online learning relies on the extensive involvement of parents of young children and in older ages on their ability to independently study. Parental involvement and independent study are obviously affected by the socio- 
economic background of the students' families and their families' cultural capital. Thus, even if we exclude the digital divide, the online learning model might nevertheless broaden existing educational gaps, (Masry-Herzallah \& Stavissky, 2021; Schleicher, 2020).

Moreover, current studies argue that the cultural context cannot be ignored in online learning (Ferreira, 2016; Jung \& Gunawardena, 2015). These studies claim that cultural aspects of teaching and learning styles must be taken into account in the technological space, and variables such as nationality, gender, tradition and values should be addressed, as they are connected to learning approaches and teaching processes in the online space and in general (Moore et al., 2005; Jung \& Gunawardena, 2015). Nonetheless, following the eruption of the Corona crisis, the transition to online learning was rapid and left schools no time for early preparations (Aboagye et al., 2020) so that it was considered as a temporary solution to an immediate problem (Bozkurt \& Sharma, 2020). The various courses were not pre-designed to be taught through online leaning and the teachers had not been properly trained to teach remotely through technological means (Alqahtani \& Rajkhan, 2020). In particular, the rapid transition to online learning has made it difficult for schools to build a curriculum based on high engagement in the learning process and to notice and emphasize students' interactions in the class. Additional difficulties for online learning may be the lack of students' readiness for online learning, which requires them to master technical skills and to have an available computer and internet network (Aboagye et al., 2020). Likewise, students and teachers who have become used to conservative face-to-face pedagogies may find it difficult to adjust to new learning styles (Watkins et al., 2004). The success of the transition to online learning differed between schools, so that some of the schools managed to transfer a relative proportion of their studies to online studies, while others experienced various difficulties because the implementation of this type of learning was influenced by various factors (Fowler, 2013; Rupp, 2016). One of these factors is the school's leadership. Many studies have indicated the positive correlations between transformational leadership and various performances (Bass, 1990; Berson et al., 2001). These studies demonstrate that insofar as the principal's leadership style is more transformational then there are more organisational performances. Since there is a broad consensus in the professional literature concerning the positive influence of transformational leadership in comparison with other leadership styles on employees' organisational performances in general and on teachers' performance in particular (Masry-Herzallah \& Arar, 2019; Ross \& Gray, 2006b), the research described here focused only on the transformational leadership style. Adopting the transformational leadership style positively influences the teachers' experiences and behaviours and the manner in which they relate to the conditions dominating the school and eventually, adoption of this leadership style leads to an improvement in the school's achievements (see the meta-analysis of Leithwood \& Sun, 2012). In order to stir their subordinates to action, transformational leaders use four main affective channels of communication: charisma, personal communication, intellectual stimulus; and interpersonal motivation (Bass \& Avolio, 1993; Hinkin \& Schriesheim, 2008). 
Transformational leaders are revealed during organisational crises and found to be more effective in these situations (Pillai et al., 2007). A transformational leader influences belief approaches and fundamental values of subordinates and consequently increases their willingness to accept changes. The transformational leadership style succeeds in impressing on subordinates the recognition of the importance of their mission to improve the level of their performances (Bass, 1985). Transformational leaders also instil a high level of aspirations among subordinates, concern for the welfare of others and recognition of the importance of the organisation's achievement and success (Bass, 1999). This style of leadership is identified with strong satisfaction and organisational commitment and was also found to help the organisation to develop more amenable employees, committed to organisational changes (Bommer et al.,2005).

Studies that examined the influence of the transformational leadership in schools found that this leadership style positively influenced teachers' commitment to school (Ross \& Gray, 2006b), commitment to organisational changes (Hallinger, 2003) and organisational functions (Abu Nasra \& Heilbrunn, 2015). In this context, research has shown that a high level of commitment formed under the transformational leadership style improves teachers' investment in their work and resilience in the face of different organisational challenges and different educational changes prevailing in the education system (Ross \& Gray, 2006b).

Successful integration of online learning in school depends on educational leaders. Research shows that transformational leadership is particularly relevant for the development of online learning (Futrell, 2011). Transformational leaders manage to adapt their leadership style to be appropriate for the change required in online learning, using different strategies such as continuous staff learning, collaborative learning in different teams, and working with the community to achieve organisational goals when implementing online learning (Onorato, 2013). Therefore, the present study hypothesizes that the school principal's transformational leadership style positively predicts the success of teachers in online teaching during the Corona pandemic that has prevailed throughout the world in the past year.

\section{Organisational communications during a period of change}

The research described here examined the mechanism by which transformational leadership contributes to the success of online teaching during the Corona crisis, and suggests that this occurs, inter alia, through improvement of the school communications. School communications relate to the transfer of information and knowledge in the school. Consequently, it is essential to understand the ways in which an organisational communications system works and the implications of this system for the organisational structure and functioning (Jablin, 1987). There is significant scholarly consensus concerning the role of the quality of communications in planning change and managing resistance to change (Van Dam et al., 2008). When employees receive useful and timely information about change, they tend to evaluate the change more positively and demonstrate greater willingness to cooperate (Miller et al., 1994; Wanberg \& Banas 2000). A strategy that helps organisations to apply changes is to broaden collaborative work, conducting continuous discussion and building trust between the leader and the 
other workers in the organisation (Courpasson et al., 2012). High levels of participation and involvement increase the employees' motivation and enable them to become more involved in the activities and gain control over the dynamic and complex environment in which they work (Leana et al., 1990). They also help managers to become more deeply acquainted with employees through their follow-up and guidance (Lines, 2004).

In the context of Online learning during the Corona pandemic and the closing of schools, school principals were forced to increase their use of online communications to correspond with all stakeholders, in order to promote school activity (Khan et al., 2020). Studies of digital leadership and Online learning conclude that communications become central tools when there is physical Online between the leader and subordinates (Kayworth \& Leidner 2002). Current studies on the role of leadership in academia during the Corona pandemic argue that constructive, clear, balanced communications, hopeful for the future and based on empathy for the individual needs of subordinates in all accessible communication channels improve the organisational climate and consequently improve outputs (Edmondson, 2020; Fernandez \& Shaw 2020a, 2020b). Studies conducted in formal organisational settings found that the transformational leadership style positively constructed clear, open, transparent and bi-directional communications, producing amenability to consultation, and inspiring or being able to provide strong rational conviction (Yuk et al., 1996). We therefore hypothesize that the quality of communications in school during the Corona pandemic mediates the correlation between transformational leadership and the success of online teaching.

\section{Online learning in the Israeli education system}

The public education system in Israel is unique in that it includes several streams, Jewish state schools, Jewish state religious schools and Arab schools. Arab education has special features. Research literature discussing the Arab education system in Israel records significant gaps in the inputs and outputs of this system in comparison with the Jewish education systems (Arar \& Masry-Herzallah, 2018; Masry-Herzallah \& Amzalag, 2021). The Arab education system endures discrimination regarding budgets, infrastructure, learning programmes and participation in decision-making in comparison to the Jewish system (Ayalon et al., 2019) and research shows huge deficiencies in the assimilation of computerization in Arab education schools in comparison to Jewish schools (Arar \& Masry-Herzallah, 2016; Masry-Herzallah \& Stavissky, 2021).

The slow introduction of the computer in Arab education enlarges digital gaps that anyway exist between Jewish and Arab societies (Ganayem, 2018). These gaps in turn influence the level of digital means use in education during routine functioning, something that necessarily influences the extent of preparedness for the use of these means for Online learning among teachers and students during the Corona pandemic (Masry-Herzallah \& Stavissky, 2021).

Recently it was found that almost half of Arab school students are not connected in a continuous manner to Online learning; in certain areas Online learning does not exist because of lack of a network infrastructure; lack of suitable end devices and a lack of parental ability to help children with computers. Moreover, there is a low level of 
preparedness in Arab schools and investment in school staff training in Arab society is lower in comparison to Jewish society. Finally, the main platforms for Online learning only appear in Hebrew, in addition to a lack of digital contents in Arabic such as film clips and presentations, in comparison to those available in Hebrew (Dahan et al., 2020). This means that in the transition to online learning, the school principal may have little influence on the success of online learning in Arab communities, since in this society there are many factors which may hinder the success of the transition to online learning. Therefore, we hypothesize that there is a gap in success of online teaching between Jewish and Arab teachers and that the variable of population sector moderates the indirect correlation between transformational leadership and success in online learning.

\section{The research goals}

The present study aimed to investigate the correlation between the school principal's transformational leadership style and the teachers' successful online teaching in the Israeli education system during the Corona pandemic, and to examine the role of school communications in this process. Moreover, the research aimed to examine the role of population sector (Jewish/Arab) on these correlations.

\section{METHOD}

\section{Participants}

Four-hundred sixty-seven male and female teachers entered the online link sent to them, with a request to answer a questionnaire on the subject of online teaching during the Corona pandemic crisis. 46 of them (9.9\%) claimed that they did not teach online at all and were omitted from the analysis. 38 additional teachers stopped completing the questionnaire after several questions and they too were omitted from the analysis. The analysis therefore related to 331 teachers ( $74.3 \%$ women), of whom $58.9 \%$ taught in the Arab sector and the remainder $(41.1 \%)$ taught in the Jewish sector. The teachers' mean age was 41.45 years $(\mathrm{SD}=8.85)$ and their mean years of experience in teaching was 15.36 years $(\mathrm{SD}=8.67)$. Most of the teachers reported that they taught in junior high schools $(41.5 \%)$ and the others taught in elementary schools $(34.3 \%)$ or senior high school (24.4\%). Approximately two thirds of the teachers reported that most of the students in their school were from an average socio-economic stratum, a minority reported that most of their students were from very low socio-economic strata $(4.5 \%)$ or low strata (13.5\%). $15.3 \%$ reported that most of their students came from a high socioeconomic stratum and $1.5 \%$ reported that most of their students came from a very high socio-economic stratum. The teachers in the sample reported that they only taught online 9.08 hours per week on average $(\mathrm{SD}=6.36)$.

\section{Tools}

The research used several questionnaires:

\section{Transformational leadership questionnaire}


Transformational leadership is measured through the conventional questionnaire proposed by Bass and Avolio: Multifactor Leadership Questionnaire: MLQ Form 5X (Avolio et al., 1999). This questionnaire originally included 36 questions, intended to measure all types of leadership according to The Full Range Leadership model. In the present study 20 statements were used, all intended to measure transformational leadership. The teachers were asked to report to what extent their school principal performed 20 different behaviours that were described to them on a scale from 1(not at all) to 5 (always). The questionnaire included three subsidiary indices: (1) charismatic influence (e.g., "acts in ways that inspire the teachers' respect"); (2) intellectual stimulus (e.g., "stimulates the teachers to look at problems from different viewpoints"); (3) personal consideration (e.g., relates to each teacher in a personal manner and not just as another one in the group). The present study used a Hebrew version of the questionnaire that was validated multiple times in Israel (Amitay et al., 2005).

\section{Communications questionnaire}

The quality of communications during the transition to online learning was measured with a questionnaire based on a tool used by Miller et al. (1994) to measure communications during organisational change. The sharp transition to online learning in the education system can definitely constitute a type of organisational change, so that this questionnaire was suitable to investigate the quality of communications during the transition to online learning during the Corona pandemic. The questionnaire was adapted to suit the present change (e.g., "the general picture that the school leadership created during this period was clear and structured"). The teachers were asked to mark the extent of their agreement with seven statements on a scale ranging from 1 (not at all) to 5 (to a very large extent).

\section{Success of online learning questionnaire}

This scale was also based on a validated questionnaire used widely in past research (Bolliger \& Wasilik, 2009). The original questionnaire included 28 statements intended to measure satisfaction concerning various aspects of online learning. Fourteen statements were chosen for the study, solely measuring the success of the teaching. The statements were intended to measure success from several angles: (1) the students' angle (e.g., "I feel that the online teaching is effective for students"); (2) the management and organisation of the lesson (e.g., "the online lessons are managed as they should be"); (3) discipline (e.g., "many students absent themselves from my online lessons" [reversed coding]; (4) active learning (e.g., "my students are actively involved in online learning"). The teachers were asked to mark to what extent these behaviours were prevalent on a scale between 1 (never) to 5 (always).

\section{A demographic questionnaire}

This part included questions to elicit demographic details such as gender, sector, age, tenure etc. Also, the teachers were asked to identify the socio-economic status of most of the students in their schools on a scale of 1-5 (from very low to very high).

\section{Procedure}


A link to an online questionnaire on a Qualtrics platform was distributed to teachers throughout Israel on $3^{\text {rd }}$ May 2020, approximately one-and-a-half months after the transition to online learning. The teachers received an explanation of the purpose of the questionnaire and were informed how to contact the researchers, in case they had further questions. They were promised that their responses would be confidential and any reports would mask their identities as anonymous, and would be used solely for the purposes of the research. Two weeks after the questionnaire was distributed, a reminder was sent to teachers who had not answered, and a month later a second reminder. The responses were collected until $9^{\text {th }}$ July,2020.

\section{Analytical Approach}

We performed hierarchical regressions to evaluate our hypotheses and used SPS'S Process macro (Hayes, 2017), which enables the investigation of a variety of models of mediation and moderation through the bootstrapping technique. Our moderationmediation model (Model 7) was assessed by the macro, which generated $95 \%$ biascorrected confidence intervals (CIs) with a bootstrap approach developed by Preacher and Hayes $(2004,2008)$ with 5,000 resamples. By using this well-known procedure, we examine the direct relationships between principal's transformational leadership and successful transition to online learning, the indirect relationships between these variables through the quality of the school's communication, and the moderating role of the school's sector.

\section{FINDINGS}

Table 1 displays the descriptive statistics for the research variables, their internal reliability according to Cronbach's $\alpha$, and correlations between the main research variables.

Table 1

Correlations between research variables, descriptive statistics and Cronbach's $\alpha(\mathrm{N}=331)$

\begin{tabular}{lllllllll}
\hline Variable & Mean & SD & 1 & 2 & 3 & 4 & 5 & 6 \\
\hline Gender $^{1}$ & 0.74 & 0.44 & - & - & - & - & - & - \\
\hline Socio-economic status $^{2}$ & 2.96 & 0.73 & $.12^{*}$ & - & - & - & - & - \\
\hline Sector $^{3}$ & 0.59 & 0.49 & - & & - & - & - & - \\
\hline & & & $-.21^{* * *}$ & $-.26^{* * *}$ & & & - & - \\
\hline Transformational leadership & 3.71 & 0.88 & 00 & $.13^{*}$ & .03 & $(.97)$ & - & - \\
\hline Communications & 3.29 & 0.74 & $.14^{*}$ & $.15^{* *}$ & -.02 & $.63^{* * *}$ & $(.86)$ & - \\
\hline Success in online teaching & 3.28 & 0.64 & -.01 & $.23^{* * *}$ & $-.18^{* *}$ & $.28^{* *}$ & $.42^{* * * *}$ & $(.89)$ \\
\hline
\end{tabular}

$*=p<.05 ; * *=p<.01 ; * * *=p<.001 ;$ bracketed figure=internal reliability;

${ }^{1}$ Dummy coding $(0=$ male, $1=$ female $) ;{ }^{2}$ the socio-economic status of most students in the school $(1=$ very low to $5=$ very high $) ;{ }^{3}$ Dummy coding $(0=$ Jewish school, $1=$ Arab school). 
Table 2

Correlations between research variables, descriptive statistics and Cronbach's $\alpha$ for Jewish teachers $(\mathrm{N}=136)$ and Arab teachers $(\mathrm{N}=195)$

\begin{tabular}{|c|c|c|c|c|c|c|c|}
\hline \multicolumn{8}{|l|}{ Jewish teachers } \\
\hline Variable & Mean & SD & 1 & 2 & 3 & 4 & 5 \\
\hline 1. Gender ${ }^{1}$ & 0.85 & 0.36 & - & - & - & - & - \\
\hline 2. Socio-economic status ${ }^{2}$ & 3.18 & 0.76 & .04 & - & - & - & - \\
\hline 3. Transformational leadership & 3.39 & 0.83 & $.20^{*}$ & .15 & - & - & - \\
\hline 4. Communications & 3.33 & 0.84 & $.26^{* *}$ & $.18^{*}$ & $.66^{* *}$ & - & - \\
\hline 5. Success & 3.45 & 0.57 & .02 & $.21^{*}$ & $.30^{* *}$ & $.45^{* *}$ & - \\
\hline \multicolumn{8}{|l|}{ Arab teachers } \\
\hline Variable & Mean & SD & 1 & 2 & 3 & 4 & 5 \\
\hline 1. Gender ${ }^{1}$ & 0.67 & 0.47 & - & - & - & - & - \\
\hline 2. Socio-economic status ${ }^{2}$ & 2.80 & 0.66 & .10 & - & - & - & - \\
\hline 3. Transformational leadership & 3.74 & 0.91 & -.09 & $.15^{*}$ & - & - & - \\
\hline 4. Communications & 3.30 & 0.70 & .05 & .14 & $.64^{* *}$ & - & - \\
\hline 5. Success & 3.21 & 0.67 & -.09 & $.20^{*}$ & $.27^{* *}$ & $.41^{* *}$ & - \\
\hline
\end{tabular}

Tables 1 and 2 clearly show that teachers teaching in the Jewish sector reported more success in online teaching during the Corona pandemic. Teachers in the Jewish sector reported that most students in their schools come from higher socio-economic strata. A strong and significant positive correlation was found between transformational leadership and the quality of communications in schools, such that when the school has a more transformational leader, then school communications were better. A significant positive correlation of medium-weak strength was also found between transformational leadership and success in online teaching, such that if the school principal had a more transformational style then the school teachers reported more success in online teaching. A significant positive correlation, of medium strength was found between the quality of school communications and success in online teaching during the Corona crisis, such that when school communications were better, the teachers reported more success in online teaching. The data in Table 1 also show that the research variables were found to have high to very high internal reliability according to Cronbach's $\alpha$.

At the next stage, the research tested whether the quality of school communications mediated the correlation between transformational leadership and success in online teaching. Moreover, the research examined whether the correlation between transformational leadership and communications was moderated by sector and whether the entire indirect correlation was moderated by the respondent's sector. An additional examination revealed that there was no interaction between transformational leadership and sector on success in online teaching, and so it was decided not to report this here. In order to test the moderated-mediation model, a bootstrap approach (Hayes, 2018) was applied to SPSS's Process macro with 5,000 resamples, at a confidence interval of $95 \%$. Hierarchical regressions were also performed. Since there was a desire to ascertain 
whether sector played a role in the model, rather than socio-economic status, it was decided to maintain the variable socio-economic status as a control variable in the model (covariate).1 This decision was made because it is known that there are large differences between the sectors in terms of their socio-economic status, as was found also in the present study. The summary of the results of the model can be seen in Table 3 .

Table 3

Results of multiple regression $(\mathrm{N}=331)$

\begin{tabular}{|c|c|c|c|}
\hline \multirow[t]{2}{*}{ Variable } & \multicolumn{2}{|c|}{ School communications } & Success in online teaching \\
\hline & Model 1 & Model 2 & Model 3 \\
\hline Socio-economic status 1 & $0.07(0.05)$ & $0.07(0.05)$ & $0.12^{* *}(0.05)$ \\
\hline Sector $^{2}$ & $-0.04(0.07)$ & $-0.04(0.07)$ & $-0.18^{* *}(0.07)$ \\
\hline Transformational leadership & $0.54(0.04)^{* * * *}$ & $0.66(0.06)^{* * * *}$ & $0.00(0.05)$ \\
\hline Communication & & & $0.33^{* * * *}(0.05)$ \\
\hline $\begin{array}{l}\text { Transformational leadership } \mathrm{x} \\
\text { sector }\end{array}$ & & $-0.17(0.07)^{*}$ & \\
\hline $\mathrm{R}^{2}$ & $.42^{* * *}$ & $.43^{* * *}$ & $.22^{* * *}$ \\
\hline
\end{tabular}

${ }^{1}$ The socio-economic status of most students in the school (1=very low to $5=$ very high); ${ }^{2}$ Dummy coding ( $0=$ Jewish school, $1=$ Arab school).

In Table 3, we show the results of the mediated-moderated model.

The effects displayed are not standardised. The variable 'transformational leadership' is centred. As can be seen in the findings for Model 1 (Table 3), (Iin Model 1, we show that transformational leadership predicts school communication, above and beyond the control variables). transformational leadership positively and relatively strongly predicted the quality of school communications. Further, the findings for Model 2 (In Model 2, we show that this relationship is moderated by sector, such that it is stronger among Jewish teachers as compared to Arab teachers), indicated that an interaction was found between transformational leadership and sector on school communications. Figure 2 illustrates the interaction according to the accepted method (Aiken, West, and Reno 1991). As can be seen in Figure 2, the correlation is strongest for teachers in schools in the Jewish sector.

As can be seen in the findings for Model 3 (Table 3), (in Model 3, we show that, in its turn, high quality school communications positively predicts success in online teaching, above and beyond the control variables), it was found that the quality of communications in turn predicts success in online teaching during the Corona pandemic. Finally, it was also found that the mediation described is moderated by sector (index = $0.06,95 \%$ CI $[-0.12,-0.004])$, so that the indirect effect is stronger for Jewish schools (indirect effect $=0.22,95 \%$ CI $[0.15,0.30]$ ) in comparison with Arab schools (indirect effect $=0.16,95 \%$ CI $[0.11,0.22])$.

1 Removing the variable did not alter the results of the model and the level of its significance. 


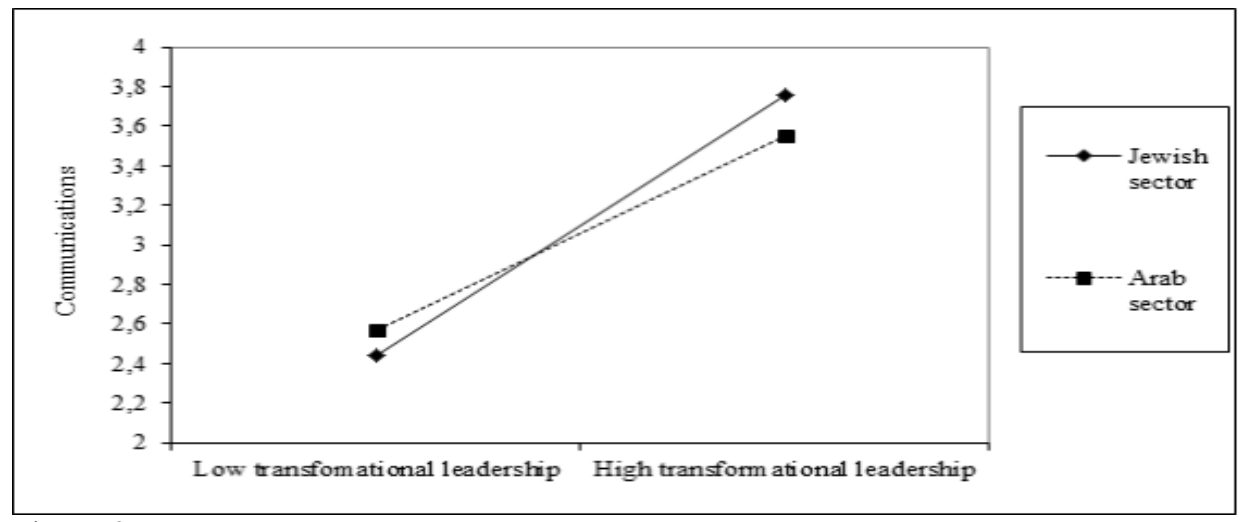

Figure 2

Interaction between sector and transformational leadership in predicting school communications.

\section{DISCUSSION}

The present study examined teachers' perceptions of the relationship between transformational leadership, school communication and success in online teaching during the period of the Corona crisis in Jewish and Arab schools in Israel. As hypothesized, the research findings indicate a positive correlation between the three variables of the study: the transformational leadership, the quality of communications and success in online teaching during Corona crisis. Likewise, students`socioeconomic status was found to be positively correlated to all major research variables. Thus, the higher socio-economic status of the school's students, the better the teachers`perception of transformational leadership, the higher quality of communications then more success in online teaching is described. Other findings indicate that the quality of communications mediates the correlation between transformational leadership and success in online teaching; and the variable 'sector' (Arab-Jewish) moderates the relationship between the transformational leadership and the quality of communications. Thus, among Jewish teachers, the correlation between transformational leadership and quality of communications' is stronger than for Arab teachers.

From an analysis of the present study, a number of insights can be attained. First, the findings highlight the great importance of the principals who employed a transformational style during this period of dynamic change for success in online teaching during the duration of the Corona crisis. These findings are in line with findings from previous studies that indicated that transformational leaders are more effective in periods of change (Pillai et al. 2007), and in the implementation of online learning (Dexter, 2011; Rupp, 2016). This finding can be explained by the fact that transformational leaders help the organisation to develop employees who are more amenable and committed to organisational change (Bommer et al., 2005). And the transformational leaders tend to see risks as challenges and encourage their subordinates to think "outside the box" and to examine familiar problems in new ways (Hater \& Bass, 1988). 
Second, the current findings expand previous work about school communications and transformational leadership. Previous work highlighted the role of communications and especially communications that rely on teachers' cooperation, trust and transparency (Courpasson et al., 2012), but no reference was made to the effect of communications on success in online teaching in periods of uncertainty such as the Corona crisis, which need management of online teaching under conditions so different from those of routine times, necessitating effective transmission of information and knowledge.

Moreover, like other studies, the present research findings indicate the importance of school communications and suggest that these communications play a significant role in the correlation between transformational leadership and success in online teaching during a crisis. These finding echoes previous findings indicating that the managers' influence on organisational behaviour and products is not direct but rather is mediated (Andreas et al., 2010; Heck \& Hallinger, 2010).

Third, the present findings shed new light on the role of sector (Jewish/ Arab) on the success of teachers in online teaching during the Corona crisis. In a comparison between Jewish and Arab teachers, the research findings revealed differences between the two sectors, such that teachers in the Jewish schools reported more success in online teaching during the Corona crisis. One possible explanation for these findings of the Jewish teachers relates to both internal and external factors affecting the Jewish schools, in addition to the teachers ${ }^{`}$ personal factors in the Jewish sector. External factors relate to the level of the policy of the Ministry of Education, i.e., the main platforms of online learning are in the Hebrew language and the majority of the contents designated for online learning are in the Hebrew language. There is a higher socio-economic stratum of the students in the Jewish schools, as the teachers reported. These findings are in line with findings from previous studies (Masry-Herzallah \& Stavissky, 2021; Perach, 2020). In addition, the cultural context also has an influence, Jewish society is considered a "Western", developed society, emphasizing technology woth a culture of innovationdriven education, so that Jewish schools prepare their graduates to integrate in a Western, innovative and technologically- oriented society (Amzalag \& Masry-Herzallah, 2021; Talavera \& Hecht, 2018). The internal factors include the school culture in Jewish schools as a collective culture, allowing teachers to think, teach and work together as a team, increasing their motivation to try new teaching methods and innovation (MasryHerzallah \& Da`as, 2020), so its` not surprising that teachers in the Jewish schools reported more success in online teaching during the Corona crisis. Thus too, the Jewish teachers' personal factors aid this process, namely the technological ability of the teacher, is relatively higher among the Jewish teachers (Masry-Herzallah \& Stavissky, 2021).

One possible explanation for the findings from the Arab teachers relates to both internal and external factors affecting behaviour in Arab society, in addition to teachers' personal factors in the Arab sector. External factors include the inequality between the Jewish and Arab education systems, the lower socio-economic status and inferior infrastructure and lack of digital devices in Arab society (Perach, 2020). These conditions led to a digital gap between the two societies both in level of usage and goals for the use of technology (Ganayem, 2018). Internal factors include the more traditional school culture 
and lack of resources required to integrate ICT in teaching in the education system, such as computer labs and teacher training for telecommunications, which influence the Arab teachers' and students' digital literacy (Arar \& Masry-Herzallah, 2016; Masry-Herzallah \& Stavissky, 2021; Masry-Herzallah \& Da`as, 2020). These findings are in line with findings of previous research that identify basic conditions essential for the success of online learning in a school in addition to the role of school leadership (Bleakley \& Mangin, 2013; Rupp, 2016).

Fourth, the present findings shed new light on the context of the correlation between school leadership and the teachers' success in online teaching, a stronger correlation was found in Jewish schools, meaning that success in online teaching among Arab teachers was explained less well by the type of leadership and quality of school communications. It therefore seems that the success of Arab teachers in online teaching is affected by additional factors. and future research should try to identify and understand them.

\section{CONCLUSION AND RECOMMENDATION}

The findings highlight the significant contribution of the principals who employed a transformational style during this period of dynamic change for success in online teaching during the period of the Corona crisis. Moreover, the present research findings indicate the importance of school communications and suggest that these communications play a significant role in the correlation between transformational leadership and success in online teaching during a crisis. This research contributes to accumulated knowledge concerning the school principal's leadership both during the period of change and in the implementation of online learning in schools. Insofar as could be ascertained, the present study is the first to investigate the role of transformational leadership in the success of online teaching during the Corona pandemic in the Israeli education system, while comparing Jewish and Arab teachers' perceptions of their success. The present findings contribute to knowledge concerning online learning during a crisis not only in the ethnic majority, but also in an ethnic minority and the factors influencing the implementation of this sort of learning, factors which are not only within the influence zone of the school principal. So it is important to examine the transition to online learning in the Israeli education system, not only in the Jewish education sector, but also in the Arab education sector that operates in unique social, educational, cultural, and political conditions. This is the first study that has been conducted comparing the views and success of Jewish and Arab teachers in Israel, the findings concerning the Jewish teachers align with other studies in Western societies and the findings concerning the Arab teachers align with other studies in other Arab societies in the world. Thus, the current research contributes new knowledge to the literature on online learning, the enhancement of existing knowledge on cultural-adapted online teaching in routine times and in times of emergency.

The findings of the present study testify that transformational leadership and the quality of communications predict teachers' successful online teaching, especially during periods of change as during the Corona pandemic. Therefore, the first practical contribution is apparently that these qualities should constitute components in school principals' training in order to increase their abilities and willingness to improve 
organisational communications in a world of uncertainty, where circumstances are dynamically changing and one of the limitations is the difficulty to predict those changes. Training processes should highlight the development of characteristic qualities of the transformational leadership style, since the transformational leader also gives expression to optimal multidimensional organisational communications including effective use of online communications. These qualities are essential to cope with varying circumstances and their dictates and create a stable grounding for the promotion of pedagogic innovation, teachers' commitment, an innovative climate and teachers' success in advancing teaching to facilitate the students' success. These processes can be expected to improve the school's perceived effectiveness, resilience and the quality of its products.

However, the findings of the study also hint that in the context of Arab teachers there may be other significant factors involved in the success of online learning. The findings show that teachers' success in online teaching in Arab society is influenced by different factors and not just school leadership, a situation which necessitates urgent intervention by policy makers to address the needs of the Arab education system and reduce discrepancies enlarged by the Corona crisis. The present research findings provide significant information for the planning of online learning in Arab society, indicating the need to reduce and not to widen gaps between the resources of Arab and Jewish societies.

\section{LIMITATIONS}

The research had several limitations. Firstly, it investigated the correlation between transformational leadership, quality of communications and teachers' success in online teaching. Additional variables may play a role in successful online learning. Future research should take additional potential variables into account when studying this issue, which may influence teachers' success in online learning. Previous literature suggests a long list of possible variables such as organisational commitment, emotional commitment, school innovation, school climate etc. Also, as noted in the literature review, few studies have researched the issue of school leadership and online learning during the Corona epidemic, so that qualitative research should also be performed to investigate the significance of this correlation from the viewpoints of teachers, principals and students.

An additional limitation was that the research did not test whether there were differences between the different education streams. such as the sub-cultures of Jewish education (religious, ultra-orthodox and secular) and Arab sub-cultures (Bedouin, Druze etc.), future research should investigate this issue.

Finally, the research was a correlative study, and as such cannot indicate the direction of the correlations and causality. For example, in schools where communication was previously good, principals are perceived as more transformational. Moreover, the participants were all teachers who reported on the research variables: leadership style, quality of communications and success in learning. Future studies should investigate 
these variables from the principals' and students' viewpoints, which may influence the reliability of the teachers' reports.

\section{REFERENCES}

Aboagye, E., Yawson, J. A., \& Appiah, K. N. (2020). Covid-19 and E-learning: The challenges of students in tertiary institutions. Social Education Research, 1-8.

Abu Nasra, M., and S. Heilbrunn. (2015). Transformational leadership and organizational citizenship behavior in the Arab educational system in Israel: The impact of trust and job satisfaction. Educational Management Administration and Leadership, 43(2), 1-17.

Alqahtani, A.Y. \& Rajkhan, A.A. (2020). E-Learning critical success factors during the Covid-19 Pandemic: A comprehensive analysis of e-learning managerial perspectives. Education Science, 10, 216.

Aiken, L. S., West, S. G., \& Reno, R. R. (1991). Multiple regression: Testing and interpreting interactions. CA: Sage.

Amitay, M., Popper, M. \& Lipshitz, R. (2005). Leadership styles and organizational learning in community clinics. The Learning Organization, 12(1), 57-70.

Andreas, K., Petros, P. \& Leonidas, K. (2010). The influence of school leadership styles and culture on students' achievement in Cyprus primary schools. Journal of Educational Administration, 482, 218-240.

Amzalag, M., Masry-Herzallah, A. (2021) Cultural Dimensions and Skills in the 21st century - the Israeli Education System as a Case Study, "Pedagogy, Culture and Society". https://doi.org/10.1080/14681366.2021.1873170

Arar, K., \& Masry-Herzallah, A. (2018). Trust among teachers and educational counselors in the Arab education system, International Journal of Leadership in Education.1-13.

Arar, K., \& Masry-Herzallah, A. (2016). Motivation to teach: the case of Arab teachers in Israel. Educational Studies, 1-17.

Armenakis, A. A., \& Harris, S. G. (2002). Crafting a change message to create transformational readiness. Journal of Organizational Change Management, 152, 169183.

Avolio, B. J., Bass, B. M, \& Jung, D. I.. (1999). Re-examining the components of transformational and transactional leadership using the multifactor leadership." Journal of Occupational and Organizational Psychology, 72(4), 441-462.

Ayalon, H., Blass, N., Feniger, Y, \& Shavit, Y. (2019). Educational inequality in Israel: From research to policy. Jerusalem, Israel: Taub Center for Research of Social Policy in Israel.

Balkar, B. (2015). Defining an Empowering School Culture (ESC): Teacher perceptions. Issues in Educational Research, 25(3), 205-225. 
Bass, B. M. (1985). Leadership and performance beyond expectations. London: Collier Macmillan.

Bass, B. M. (1990). From transactional to transformational leadership: Learning to share the vision. Organizational Dynamics, 18(3), 19-31.

Bass, B. M. (1999). Two decades of research and development in transformational leadership. European Journal of Work and Organizational Psychology, 8(1), 9-32.

Bass, B. M., \& Avolio, B. J. (1994). Transformational leadership and organizational culture. The International Journal of Public Administration, 17(3-4), 541-554.

Bass, B. M., \& Avolio, B. J. (1993). Transformational leadership: A response to critiques. In M. M. Chemers \& R. Ayman (Eds.) Leadership theory and research: Perspectives and direction. (pp. 49-80). USA: Academic Press.

Bawuro, F. A., Danjuma, I. \& Wajiga, H. (2018). Factors influencing innovative behaviour of teachers in secondary schools in the North East of Nigeria. Path of Science, 4(3), 1007-1017.

Bernerth, J. (2004). Expanding our understanding of the change message. Human Resource Development Review, 3(1), 36-52.

Berson, Y., Shamir, B., Avolio, B. J..\& Popper, M.. (2001). The relationship between vision strength, leadership style, and context. The Leadership Quarterly, 1(21), 53-73.

Bleakley, D. A., \& Mangin, M. M. (2013). Easier said than done: Leading technology integration. Journal of Cases in Educational Leadership, 16(1), 14-26.

Bolliger, D. U., \& Wasilik, O. (2009). Factors influencing faculty satisfaction with online teaching and learning in higher education. Distance Education, 30(1), 103-116.

Bommer, W. H., Rich, G. A., \& Rubin R. S. (2005). Changing attitudes about change: Longitudinal effects of transformational leader behavior on employee cynicism about organizational change. Journal of Organizational Behavior: The International Journal of Industrial, Occupational and Organizational Psychology and Behavior, 26(7), 733753.

Bozkurt, A., \& Sharma, R. C. (2020). Emergency remote teaching in a time of global crisis due to CoronaVirus pandemic. Asian Journal of Distance Education, 15(1), i-vi.

Burdina, M.G., Krapotkina, I. E., \& Nasyrova, L. G. (2019). Distance Learning in Elementary School Classrooms: An Emerging Framework for Contemporary Practice. International Journal of Instruction, 12(1), 1-16. https://doi.org/10.29333/iji.2019.1211a

Chauhan, V. (2017). Synchronous and asynchronous learning. Imperial Journal of Interdisciplinary Research, 3(2).

Courpasson, D., Dany, F. \& Clegg, S. (2012). Resisters at work: Generating productive resistance in the workplace. Organization Science, 23(3), 801-819.

Dahan, Y., Abu-Rabia-Queder, S., Yona, Y. et al. (2020). Corona crisis and its effect on the israeli education system. Expert Crisis Staff, Education staff. [Hebrew] 
Dexter, S. (2011). School technology leadership: Artifacts in systems of practice. Journal of School Leadership, 21(2), 166-189.

Edmondson, A. C. (March 6, 2020). Don't hide bad news in times of crisis. Harvard Business Review.

Retrieved

from: https://hbr.org/2020/03/dont-hide-bad-news-in-times-of-crisis

Fedynich, L., Bradley, K. S., \& Bradley, J. (2015). Graduate students' perceptions of online learning. Research in Higher Education Journal, 27,1.

Fernandez, A., \& Shaw, G. (2020a). Leadership in higher education in an era of adaptive challenges. In International Technology, Education and Development Conference. (pp. 61- 65). Valencia, Spain: IATED Academy

Fernandez, A. A., and G. P. Shaw. (2020b). "Academic Leadership in a Time of Crisis: The Coronavirus and COVID-19." Journal of Leadership Studies, 14(1), 39-45.

Ferreira, D. (2016). Bridging the cultural gap of online learning: Implications and strategies. Language Research Bulletin, 31, 8-15.

Fowler, F.C. (2013). Policy studies for educational leaders. 4th ed. Boston: Pearson.

Fullan, M. (2007). Leading in a culture of change. San Francisco: John Wiley and Sons.

Futrell, M. H. (2011). Redefining leadership: Working together to change America's education paradigm and prepare for tomorrow's world. Journal of School Leadership, 21(4), 635-648.

Ganayem, A. (2018). The Internet in the Arab society in Israel: The situation, gaps and recommendations for advancement in digitization. In Conference on Making Digital Public Services Accessible to the Arab Society. Kfar Kassam: Israeli Internet Association.

Hallinger, P. (2003). Leading educational change: Reflections on the practice of instructional and transformational leadership." Cambridge Journal of Education, 33(3), 329-352.

Hater, J. J., \& Bass, B. M. (1988). Superiors' evaluations and subordinates' perceptions of transformational and transactional leadership. Journal of Applied Psychology, 73(4), 695-702. https://doi.org/10.1037/0021-9010.73.4.695

Hayes, A. F. (2018). Introduction to mediation, moderation, and conditional process analysis: A regression-based approach. New York, NY: Guilford Press.

Heck, R. H., \& Hallinger, P.. (2010). Testing a longitudinal model of distributed leadership effects on school improvement. Leadership Quarterly, 21(5), 867-885. Retrieved from: https://doi.org/10.1016/j.leaqua.2010.07.013

Hinkin, T. R., \& Schriesheim, C.A. (2008). A theoretical and empirical examination of the transactional and non-leadership dimensions of the Multifactor Leadership Questionnaire MLQ." The Leadership Quarterly, 19(5), 501-513. 
Ismail, S. N., Abdullah, A. S., \& Abdullah, A. G. K. (2019). The Effect of School Leaders' Authentic Leadership on Teachers' Job Stress in the Eastern part of Peninsular Malaysia. International Journal of Instruction, 12(2), 67-80. https://doi.org/10.29333/iji.2019.1225a

Jablin, F. M. (1987). Formal organization structure. In F.M.Jablin and Linda Putman, (Eds.) Handbook of organizational communication: An interdisciplinary perspective, (pp. 389-419). USA: Sage.

Jung, I., \& Gunawardena, C. N. (2015). Culture and online learning: Global perspectives and research. USA: Stylus Publishing, LLC.

Kayworth, T. R., \& Leidner, D.A. (2002). Leadership effectiveness in global virtual teams. Journal of Management Information Systems, 18(3), 7-40.

Khan, M., Ismail, F., \& Hussain, A. (2020). The interplay of leadership styles, innovative work behavior, organizational culture and organizational citizenship behaviour. Sage Open, 10(1). https://doi.org/10.1177\%2F2158244019898264

Leana, C. R., Locke, E. A. \&Schweiger, D. M. (1990). Fact and fiction in analyzing research on participative decision making: A critique of Cotton, Vollrath, Froggatt, Lengnick-Hall, and Jennings. Academy of Management Review, 15(1), 137-146.

Leithwood, K., \& Sun, J. (2012). The nature and effects of transformational school leadership: A meta-analytic review of unpublished research. Educational Administration Quarterly, 48(3), 387-423.

Lines, R. (2004). Influence of participation in strategic change: Resistance, organizational commitment and change goal achievement. Journal of Change Management, 4(3), 193-215.

Masry-Herzallah, A \& Arar, K. (2019). "Gender, school leadership and teachers' motivation: The key role of culture, gender and motivation in the Arab education system" International Journal of Educational Management, 33(6), 1395-1410.

Masry-Herzallah, A \& Da`as, R. (2020) "Cultural values, school innovative climate and organizational affective commitment: a study of Israeli teachers. International Journal of Educational Management. https://doi.org/10.1108/IJEM-06-2020-0302

Masry-Herzallah, A., Stavissky Y. (2021) "The Attitudes of Elementary and Middle School Students and Teachers towards Online Learning during the Corona Pandemic Outbreak". Journal of SN Social Sciences, 1(3), 71. https://doi.org/10.1007/s43545-02100083-Z

Masry-Herzallah, A., Amzalag, M. (2021). " From theory to practice: Jewish and Arab students in academia practice education for multiculturalism". International Journal of Comparative Education and Development. Vol. ahead-of-print No. ahead-ofprint. https://doi.org/10.1108/IJCED-06-2020-0031

Masry-Herzallah, A. (2021). Education for multiculturalism in a master's degree program in policy and administration in education: comparing Jewish and Arab students 
in Israel. European Journal of Educational Research, 10(2), 757772. https://doi.org/10.12973/eu-jer.10.2.757

Miller, V. D., Johnson, J. R., \& Grau, J. (1994). Antecedents to willingness to participate in a planned organizational change. Journal of Applied Communication Research, 22, 59-80.

Moore, J. L., Dickson-Deane, C., \& Galyen, K. (2011). e-Learning, online learning, and distance learning environments: Are they the same? The Internet and Higher Education, 14(2), 129-135.

Mumford, M. D., Zaccaro, S. J. Harding, F. D. Jacobs, T. O., \& Fleishman., E. A. (2000). Leadership skills for a changing world: Solving complex social problems. The Leadership Quarterly, 11(1), 11-35.

Onorato, M. (2013). Transformational leadership style in the educational sector: An empirical study of corporate managers and educational leaders. The Academy of Educational Leadership Journal, 17, 33.

Perach, G. (2020). Arab society's response to the Corona crisis. Higher Follow-Up Committee. [Hebrew]

Pillai, R., Kohles, J. C. \&. Bligh, M. C. (2007). Through thick and thin? Follower constructions of presidential leadership amidst crises, 2001 - 2005. In B. Shamir, R. Pillai, M. C., Bligh, and M. Uhl-Bien (Eds.) Follower-Centered Perspectives on Leadership: A Tribute to the Memory of James R. Meindl (pp. 135-165). Greenwich, CT: Information Age Publishing.

Rajab, K. D. (2018). The effectiveness and potential of E-learning in war zones: An empirical comparison of face-to-face and online education in Saudi Arabia. IEEE Access, 6, 6783-6794.

Reichers, A. E., Wanous, J. P., \& Austin, J.T. (1997). Understanding and managing cynicism about organizational change. Academy of Management Perspectives, 11(1), 48-59.

Reid-Martinez, K., \& Grooms, L. D. (2018). Online learning propelled by constructivism. In Encyclopedia of Information Science and Technology, $4^{\text {th }}$ ed. (pp. 2588-2598). IGI Global.

Richardson, P., \& Denton, D. K. (1996). Communicating Change. Human Resource Management, 35(2), 203-216.

Ross, J. A., \& Gray, P. (2006a). School leadership and student achievement: The mediating effects of teacher beliefs. Canadian Journal of Education/Revue Canadienne de L'éducation, 798-822.

Ross, J. A., \& Gray, P. (2006b). Transformational leadership and teacher commitment to organizational values: The mediating effects of collective teacher efficacy. School Effectiveness and School Improvement, 17(2), 179-199. 
Rupp, N. K. (2016). Online learning and effective leadership: The importance of relationship building and culture. $\mathrm{PhD}$ dissertation, Old Dominion University.

Schweiger, D. M., and Denisi, A. S. (1991). Communication with employees following a merger: a longitudinal field experiment. Academy of Management Journal, 34(1), $110-135$.

Sproull, L., Kiesler, S. \&. Kiesler, S.B. (1991). Connections: New ways of working in the networked organization. Boston:MIT Press.

Talavera, A., \& Hecht, R. B. (2018). Israel-Middle East Mavericks. American Ceramic Society Bulletin, 97(8).

Thien, L. M., \& Adams, D. (2019). Distributed leadership and teachers' affective commitment to change in malaysian primary schools: The contextual influence of gender and teaching experience. Educational Studies, 1-21.

Van Dam, K., Oreg, S.\&.Schyns, B. (2008). Daily work contexts and resistance to organisational change: The role of leader-member exchange, development climate, and change process characteristics. Applied Psychology, 57(2), 313-334.

Wanberg, C. R., \& Banas, J.T. (2000). Predictors and outcomes of openness to changes in a reorganizing workplace. Journal of Applied Psychology, 85(1), 132-142.

Yahay, Z., \& Raman, A. (2020). Latest relationship between principals' technology leadership and teachers' technology use in secondary school. Social Science and Humanities Journal, 4(3), 1797-1814.

Yukl, G. (2010). Leadership in organizations. Upper Saddler River. New Jersey: Pearson.

Yukl, G., Kim, H. \& Falbe, C.M. (1996). Antecedents of Influence Outcomes. Journal of Applied Psychology, 8(13), 309-317.

Yuliyatno, Mustaji, \& Sitompul, N. C. (2019). Exploring the Implementation of WeblogBased Flipped Classroom in Teaching Civics: Is It Feasible and Effective? International Journal of Instruction, 12(4), 239-250. https://doi.org/10.29333/iji.2019.12415a

Watkins R, Leigh D, \& Triner D. (2004). Assessing readiness for e-learning. Performance Improvement Quarterly, 17(4), 66-79

Welner, K. G. (2020). NEPC review: Public-private virtual-school partnerships and federal flexibility for schools during COVID-19. In Boulder, CO: National Education Policy Cente. http://nepc.colorado.edu/thinktank/coronavirus 